\title{
Predicting asphalt pavement temperatures as an input for a mechanistic pavement design in Central-European climate
}

\author{
S. Cho \& C. Tóth \\ Department of Highway and Railway Engineering, Budapest University of Technology and Economics, \\ Hungary \\ P. László \\ Fulton Hogan Infrastructure Services, Australia
}

\begin{abstract}
The bearing capacity of asphalt pavements is highly influenced by the modulus of the asphalt layers, which is a function of the temperature observed in depth. The temperature dependency of each layer is also influenced by the composition of the asphalt mix.

The impact of the climatic conditions is usually considered in national pavement design guidelines by the application of the equivalent temperature. This approach however may lead to incorrect pavement designs due to its simplistic nature and cannot consider the local climatic variations.

The modulus of each asphalt layer can be modelled only if the temperature in depth is known or correctly predicted. The research work presented in this paper provides a methodology for predicting in depth pavement temperatures by using ambient and surface temperatures. These input values can be obtained at a higher frequency and at lower capital investment compared to in depth pavement temperatures.

The methodology has been validated based on long-term data collected at various depths in a full depth asphalt pavement in Budapest region. The methodology provides valuable input into mechanistic pavement design, where the performance of innovative materials can be considered. With this approach real performance prediction is enabled, which would not be possible with the simplistic method of the equivalent temperature......
\end{abstract}

Keywords: Asphalt temperature estimation, central European pavement, climate input, in-depth temperature, temperature regression

\section{INTRODUCTION}

The bearing capacity of asphalt pavements is highly influenced by the modulus of the asphalt layers, which is a function of the temperature observed in depth. The temperature dependency of each layer is also influenced by the composition of the asphalt mix; due to the complexity of this issue this characteristic will not be examined in this paper. In mechanistic-empirical design the climatic condition is major input [1]. Therefore, the importance of dealing with temperature for pavement designers takes huge part in the design process.

The impact of the climatic conditions is usually considered in national pavement design guidelines by the application of the equivalent temperature. This approach however may lead to incorrect pavement designs due to its simplistic nature and cannot consider the local climatic variations. 
From the application of the real weather data into estimation of asphalt pavement done for the first time by Barber [2], many studies regard to this subject is still ongoing [3] [1] [4] [5] [6]. Another study by Dempsey estimated asphalt in depth temperatures by monographs [5]. Matic et al. developed a model which describes the maximum and minimum temperature at specified depth with regression method [6].

The modulus of each asphalt layer can be modelled only if the temperature in depth is known or correctly predicted due to its viscoelastic characteristic of asphalt mixes [7]. The research work presented in this paper provides a methodology for predicting in depth pavement temperatures by regression method using on-site measured surface temperatures. These input values can be obtained at a higher frequency and at lower capital investment compared to in depth pavement temperatures.

The methodology has been validated based on long-term data collected at various depths in a full depth asphalt pavement in the Budapest region. The methodology provides valuable input into mechanistic pavement design, where the performance of innovative materials can be considered. With this approach real performance prediction is enabled, which would not be possible with the simplistic method of the equivalent temperature.

In this paper, the German asphalt temperature prediction model is firstly chosen to estimate an in-depth temperature profile [4] — secondly, a suggestion of a new asphalt temperature prediction model for the Hungarian climatic condition.



Figure 1. Surface temperature appearance.

Figure 1 shows the Hungarian asphalt's surface temperature distribution. Unlike German's asphalt surface temperatures, Hungary does not have any values under $-10{ }^{\circ} \mathrm{C}$. For a year, a Hungarian pavement structure's temperature at various depths were recorded for every 10 minutes. By utilizing these data sets, the temperatures were divided into 22 groups, which frequently appears for Hungarian pavement structure by $3^{\circ} \mathrm{C}$ of the interval from minimum $-5^{\circ} \mathrm{C}$ to a maximum $61^{\circ} \mathrm{C}$. 


\section{TEMPERATURE ESTIMATION MODEL}

\subsection{The German model}

Asphalt mixture displays a viscoelastic characteristic, which means its strength is affected by both the temperature and loading frequency [8].

To find the suitable Hungarian asphalt in-depth temperature estimation method, we reference the German design method. This German design method categorizes the asphalt surface temperature into 13 groups, by $5^{\circ} \mathrm{C}$ range [4]. The German temperature prediction model for the asphalt layer is predicted according to Eq. (1):

$$
y=a \cdot \ln (0.01 \cdot x+1)+T
$$

where, $y$ is asphalt temperature $\left({ }^{\circ} \mathrm{C}\right)$ at depth $x(\mathrm{~mm}), T$ is surface temperature $\left({ }^{\circ} \mathrm{C}\right)$, and $a$ is a parameter as a function of $T$.

\subsection{New model}

The German temperature estimation model shows some deviation compared to the Hungarian measured data - due to the latitude and daylight hours difference - these matter on the asphalt temperature variation inside the depth. From the static data, asphalt temperature along depth does not change instantly as the air or sudden surface temperature drop. Therefore, the need to correct the function coefficient arises as per the weather condition of Hungary, Figure 3.

Table 1. Pavement system description.

\begin{tabular}{lll}
\hline & Depth from the surface[cm] & Type \\
\hline Asphalt & 4 & AC-12/F \\
& 6 & AC-20/F \\
& 9 & AC-35/F \\
Base & 20 & CTB \\
Subgrade & 30 & Unbound \\
\hline
\end{tabular}

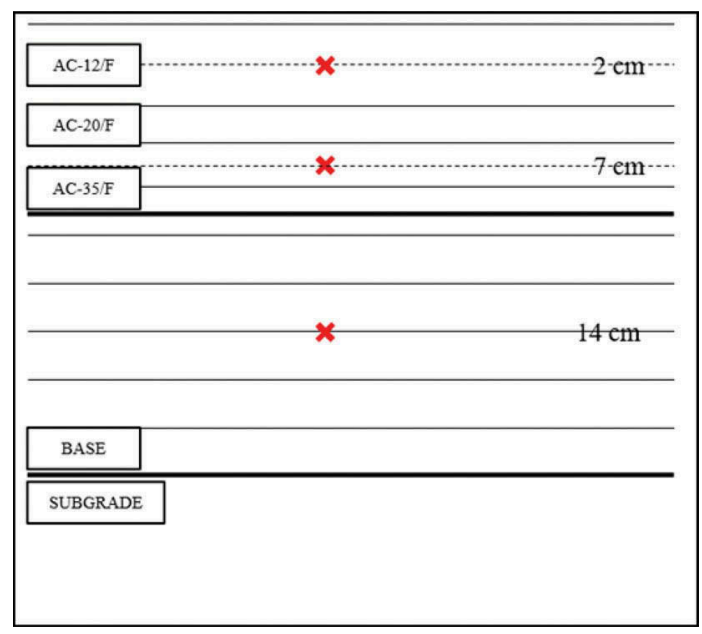

Figure 2. Sensor location. 
The new model with Hungarian weather condition is prepared by using the site measured data in central region of Hungary. The pavement system is composited with Table 1 condition, and the temperature sensor is located at the point of 2, 7, $14 \mathrm{~cm}$ from the surface. The new model is prepared by using the mixture type described in Table 1.

One weather station in the Budapest region is selected for this study (Figure 2). Following the nonlinear temperature distribution along with asphalt depth, square root and logarithm envelope functions are considered. The $5 \mathrm{~cm}$ point is the critical point where the speed of divergence of those two functions creates a gap. The logarithm function, like the German model, shows much higher disagreement after this point with measured data. Thus, the square root function is chosen to represent the temperature estimation for Hungarian weather condition with more simplicity in the formation, equation (2):

$$
y=a \cdot \sqrt{x}+T_{0}
$$

where, $y$ is asphalt temperature $\left({ }^{\circ} \mathrm{C}\right)$ at depth $x(\mathrm{~cm}), T$ is surface temperature $\left({ }^{\circ} \mathrm{C}\right)$, and $a$ is a parameter as a function of $T$ which is shown in Table 2 .

Table 2. Parameter $a$ as a function of surface temperature.

\begin{tabular}{lllllllllllr}
\hline Temperature $\left[{ }^{\circ} \mathrm{C}\right]$ & $\leq 0$ & $\leq 5$ & $\leq 10$ & $\leq 15$ & $\leq 20$ & $\leq 25$ & $\leq 30$ & $\leq 35$ & $\leq 40$ & $\leq 45$ & $<45$ \\
\hline Parameter $a[-]$ & 1.669 & 2.446 & 3.044 & 1.449 & 1.154 & 1.553 & 1.086 & -0.9228 & -1.3158 & -2.0504 & -3.5124 \\
$\mathrm{R}^{2}$ & 0.9969 & 0.9938 & 0.9773 & 0.9819 & 0.9949 & 0.8528 & 0.6896 & 0.7139 & 0.9162 & 0.8445 & 0.8948 \\
\hline
\end{tabular}

\section{VERIFICATION OF THE NEW MODEL}

Due to the speed of disagreement below $5 \mathrm{~cm}$ point increases drastically, new model has to be developed. The $5 \mathrm{~cm}$ point is the critical point where the speed of divergence. The logarithm function, like the German model, shows much higher disagreement after this point with measured data. On the other hand, the root function shows good correlation with the on-site measured value (Figure 3).

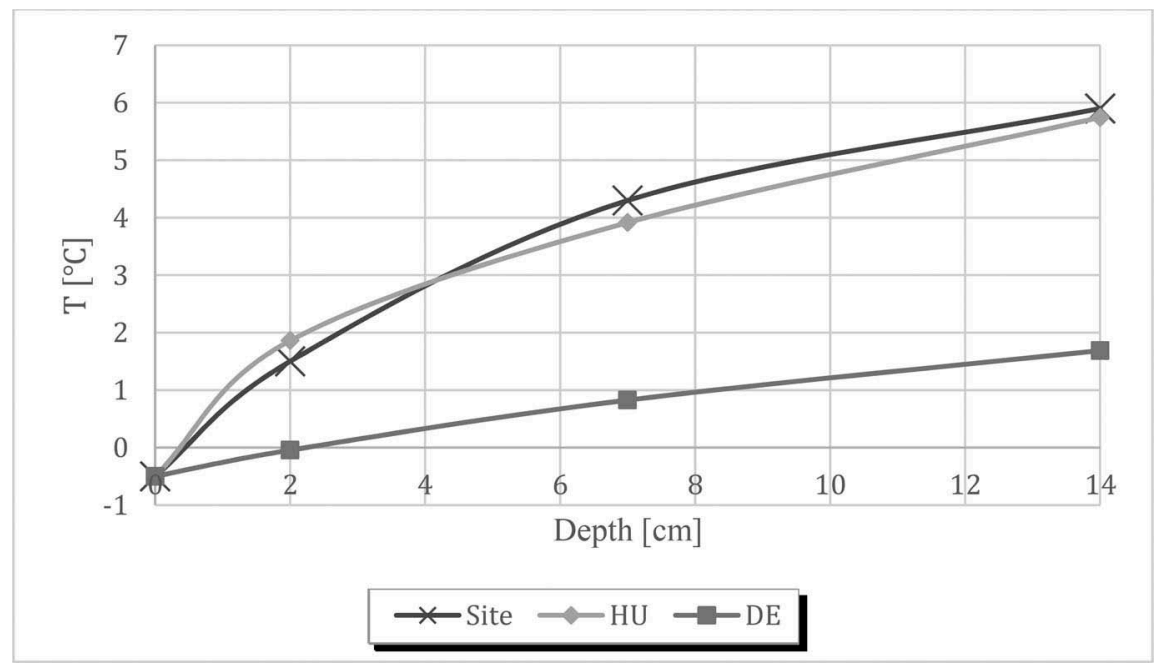

Figure 3. Site measured data and estimation models when the surface temperature is $-0.5^{\circ} \mathrm{C}$. 


\subsection{Calculation result of the Hungarian model}

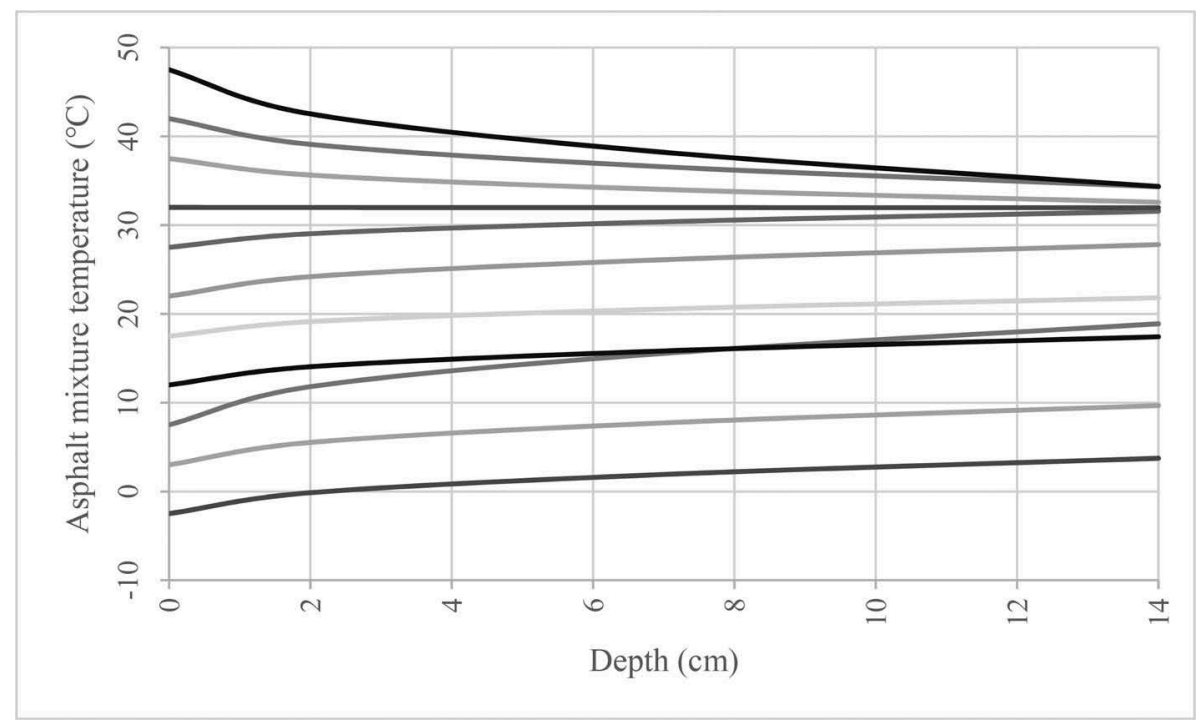

Figure 4. Temperature in-depth profile estimation by the new method with Hungarian weather data.

The Figure 4 shows the asphalt temperature distribution along the depth by the new prediction model (equation 2).

\subsection{Error tolerance of the Hungarian model}

The new model is prepared with a statical analysis and optimization result of Hungarian weather data. A yearly measured data is used for the method of Least Squares-a norm (L2, Euclidean Norm)-regression analysis is done. Result of the regression analysis is shown in Table 2, and the Table 3 shows the L2 loss comparison which shows how much the models are scattered from the site measured values (eq (3),(4)).

Table 3. L2 loss comparison between new model used here and German model.

\begin{tabular}{lllclllr}
\hline & Depth $[\mathrm{cm}]$ & \multicolumn{5}{c}{ Depth $[\mathrm{cm}]$} \\
\hline New & 2 & 7 & 14 & German & 2 & 7 & 14 \\
model & 1.460 & 1.616 & 2.245 & model & 0.444 & 1.473 & 1.811 \\
& 1.026 & 0.925 & 1.683 & & 0.680 & 3.800 & 5.000 \\
& 2.605 & 3.554 & 4.790 & & 1.682 & 4.500 & 6.600 \\
& 1.249 & 1.334 & 1.422 & & 0.745 & 2.500 & 4.000 \\
& 0.132 & 0.647 & 0.682 & & 1.427 & 3.700 & 5.000 \\
& 0.496 & 0.109 & 0.089 & & 3.483 & 0.578 & 1.921 \\
& 0.648 & 1.194 & 1.876 & & 1.204 & 2.602 & 3.708 \\
& 0.187 & 3.275 & 4.965 & & 0.930 & 0.010 & 0.428 \\
& 2.461 & 2.481 & 2.423 & & 2.150 & 3.510 & 4.941 \\
& 0.900 & 3.075 & 3.828 & & 1.886 & 2.928 & 2.308 \\
& 0.467 & 3.307 & 3.658 & & 4.407 & 12.283 & 16.186 \\
Sum & 60.809 & & & 75.951 & & \\
\hline
\end{tabular}


The norm of these two prediction models is compared, see Table 3. Overall, the new model's norm is smaller than the German model. Thus, the statement can be delivered that the new model suits on Central European climatic condition. The model coefficient's $\mathrm{R}$-squared values are given in Table 3 .

$$
\begin{gathered}
\|x\|_{2}:=\left(\sum_{i=1}^{n}\left|x_{i}\right|^{2}\right)^{1 / 2} \\
L=\sum_{i=1}^{n}\left(y_{i}-f\left(x_{i}\right)\right)^{2}
\end{gathered}
$$

where $\mathrm{n}$ is the element number, $y_{i}$ is a real value and $f\left(x_{i}\right)$ is an estimated value and $L$ means L2 loss which is Least squares error.

\section{SUMMARY AND FUTURE PLAN}

The bearing capacity of the asphalt is highly dependent on temperature due to its viscous nature. The stiffness is the function of temperature. Therefore, this temperature can be stated as the key input of Mechanistic-Empirical design. Much reliable temperature estimation brings a much realistic service life estimation.

This study is about a prediction of Hungarian asphalt layer's temperature. A prediction model is prepared for the asphalt layer's temperature estimation without direct investigation. Many of study were referenced, and among those studies the German mathematical method is chosen for this study due to the close geographical location. From the temperature properties of asphalt, this study puts the latitude for the first place and further developed the German model for the preparation of Hungarian model.

Throughout the few regressions of one year data set of Hungarian asphalt temperatures, a model for the Hungarian pavement is prepared. The $\mathrm{R}$-squared values are generally above 0.84 , except for two temperature ranges where they were found as 0.69 and 0.71 ; these values are considered reliable for temperature prediction models. The norm of the new model is given in Table 3. This study utilizes one sites' measurements set therefore a limitation comes for the generalization, however, with a following further modification with more sites and much longer time measurements will be expected to cover up such limitation.

\section{REFERENCES}

AASHTO, 2008. Mechanistic-empirical pavement design guide. Washington D.C.: American Association of State Highway and Transportation Officials.

AASHTO, 2011. LTPP computed parameter; Dynamic modulus, McLean: U.S. Department of Transportation.

Barber, E. S., 1957. Calculation of Maximum Pavement Temperature from Weather Reports, Highway Research Board Bulletin.

Dempsy, B. J., 1987. Characterizing Temperature Effects for Pavement Analysis and Design, Transportation Research Record.

Huang, Y., 2004. Pavement design and analysis. New York: Prentice Hall.

NCHRP, 2011. LTPP Computed Parameter: Dynamic modulus, US Department of Transportation Federal Highway Administration.

RDO, 2009. Guidelines for mathematical dimensioning of foundations of traffic surfaces with a course asphalt surface, Berlin: Research society for roads and traffic. 